\title{
La revolución de 1840: la culminación del Madrid progresista
}

\author{
Javier PÉREZ NúÑEZ \\ Universidad Autónoma de Madrid \\ javier.perez@uam.es
}

Recibido: $28 / 02 / 2014$

Aceptado: 12/06/2014

\section{RESUMEN}

Este artículo profundiza en la revolución de 1840, apenas estudiada por los historiadores. Después de clarificar los principales conceptos, se centra en el caso paradigmático de Madrid. Lo hace, de una parte, constatando como los liberales progresistas controlan totalmente el poder local de Madrid. Y, de otra parte, observando como los moderados desde el poder central quieren implantar una contrarreforma del régimen constitucional de 1837. El Madrid progresista encabezó la oposición a la reacción conservadora y dirigió la revolución nacional de 1840, en cuyo desarrollo observamos sus distintas caras.

Palabras clave: régimen constitucional de 1837, Madrid, revolución de 1840, ayuntamiento de Madrid, liberales progresistas, liberales moderados.

\section{The revolution of 1840: the success of progressive liberal Madrid}

\begin{abstract}
ABSTACT
This article explores the revolution of 1840 , barely studied by historians. After clarifying the main concepts, focuses on the development of the paradigmatic case of Madrid. It does, on the one hand, looking like progressive liberals totally control the local power of Madrid. And, on the other hand, watching the moderate liberals from central power want to implement a reform conservative in the constitucional system of 1837. The progressive liberal Madrid head the opposition to a conservative reform and lead the national revolution of 1840 , in whose development we observe its different faces.
\end{abstract}

Key words: constitutional system of 1837, Madrid, revolution of 1840, council of Madrid, progressive liberals, conservatives.

Referencia normalizada

Pérez Núñez, AJ. (2014). "La revolución de 1840: la culminación del Madrid progresista”. Cuadernos de Historia Contemporánea, Vol. 36, páginas 141-164.

Sumario: 1.Introducción: revolución e insurrección. 2. De la frustración insurreccional a la vanguardia del progresismo. 3. La defensa constitucional frente a la transacción conservadora. 4. Preparativos para la insurrección. 5. El glorioso pronunciamiento. 6. Las caras del Madrid insubordinado 


\section{Introducción: revolución e insurrección}

(...) "Sabido es, Excmo. Señor, en buenas doctrinas de derecho público, que cuando los cuerpos colegisladores infringen la Constitución, en orden de la cual existen y obran, quedan no sólo disueltos de derecho, sino desposeídos de la facultad legislativa. (...) el convencimiento unánime de que el pacto constitucional fue violado, impulsó al pueblo a usar el derecho imprescriptible de insurrección." (...)

[Exposición de la Junta de Madrid al Ministerio-Regencia, 15 de octubre de 1840].

La historiografía ha designado a la movilización popular del verano de 1840 como una revolución. No creemos que lo fuera. No, porque los movilizados no se levantaron contra el régimen político vigente de 1837, que fue la propia bandera de la insubordinación, sino contra su desnaturalización por los desarrollos legislativos que estaban llevando y proyectaban llevar a cabo los moderados desde el poder. En este sentido, dado que lo que se pretendía era restablecer el orden constitucional conculcado y no instituir otro nuevo, parece que fue ante todo la expresión del ejercicio del derecho a la resistencia o a la insurrección.

Así entendieron y explicaron la propia insubordinación los principales protagonistas. Lo hicieron, dentro del ideario liberal, siguiendo muy de cerca la doctrina elaborada por John Locke, gran oráculo del primer pensamiento liberal español, al considerar el pronunciamiento como un acto de legítima defensa de los gobernados frente a la arbitrariedad del poder. Evidentemente, esta actuación se asentaba en el principio de la soberanía nacional y su finalidad era recuperar el orden político establecido, del que la nación soberana era su base y fundamento.

El término citado de pronunciamiento también lo usaron los sublevados para referirse a su movilización, si bien con menor frecuencia. Además, cuando lo acogieron lo contemplaron de una manera superlativa, como el gran pronunciamiento nacional y el más glorioso de todos. Lo señalaron así, no sólo porque fuera último y en él se acumulara la experiencia de los anteriores, perfeccionando sus principales rasgos (reasunción de la soberanía por el pueblo, instauración de juntas, respaldo militar $\mathrm{y}$, en éste, especialmente de la milicia nacional), sino porque, aunque mantuviera el carácter defensivo, característico de los del tiempo isabelino, se presentaba como el de la plena y definitiva consolidación del régimen liberal.

Esta perspectiva es la que nos ha decidido a seguir utilizando en el título el término revolución. Los sublevados, salvo los republicanos, no emplearon este vocablo para designar a la insurrección. Todo indica que querían distanciarse de la connotación peyorativa machaconamente realizada por los conservadores, identificándolo con radicalismo, violencia, trastorno... Con todo, aunque para presentarse como personas de orden, respetables y responsables, excluyeran la palabra revolución de su vocabulario, la movilización de 1840 que protagonizan, atendiendo a los hechos y a los resultados, tiene algunas dosis de ella. Así, está bastante generalizada la idea de ver a esta insurrección como un retorno a la del verano de 1836, para reconducir la reforma de la Constitución de 1812 recuperada entonces de forma menos conservadora a como se había hecho o, lo que era algo parecido, reinterpretar la Constitución de 1837 de manera más parlamentaria o con un enfoque más doceañista. Además, anticipándose 
a esta orientación demandada, la renuncia de María Cristina a la Regencia, debida a la propia presión de los insubordinados, por lo excepcional y rupturista claramente es un hecho revolucionario.

El otro aspecto antes citado y que también nos reubica en ese primer Código político español es el que nos ha impelido como hemos subrayado a mantener la identidad revolucionaria de la movilización de 1840. Así esta fecha se contempla como la del triunfo definitivo e irreversible del Estado liberal y del régimen representativo constitucional, después de una denodada y cruenta lucha de más de 30 años contra el absolutismo, fernandino y carlista. De esta manera, la Revolución Liberal iniciada en 1808 por fin alcanza la meta en $1840^{1}$.

\section{De la frustración insurreccional a la vanguardia del progresismo}

Fue el Madrid progresista el que dirigió la revolución de 1840. Adquirir esta posición de liderazgo de la España insurreccional no fue nada fácil, ni dentro del ámbito político-ideológico del liberalismo avanzado, internamente dividido, ni a nivel territorial, superando las suspicacias que generaba su condición de capital del Reino e identificación con el poder central. Fue complicado porque, a pesar de haber ganado mucho terreno las tendencias progresistas, no fue el suficiente como para lograr incorporar a la provincia de Madrid y, principalmente, a su capital a las movilizaciones insurreccionales de los veranos de 1835 y 1836, particularmente a esta última, en la que, pese a intentarlo en dos ocasiones, no pudieron superar a las fuerzas militares gubernativas. Esta situación provocó una cierta frustración, no tanto porque el impulso decisivo para el cambio liberal proviniera de la insubordinación de las provincias y no de la del centro, como porque siendo este el lugar donde el progresismo y sus adláteres contaban con mayores adhesiones, sin embargo iba a la zaga al no poder hacer frente a un potencial armado muy superior en razón a la capitalidad y sede de la Corte. Las cosas cambiarían a partir de agosto de 1836 con el restablecimiento provisional de la Constitución de Cádiz.

Ante este retorno, dentro del progresismo, también en el madrileño, se esbozaron dos tendencias, no nítidamente delimitadas y definidas. De una parte, la más rezagada o liberal a ultranza que defendía la instauración de un sistema político que, acorde con los imperantes en la Europa liberal, transitara entre los que considera retrógrado

\footnotetext{
1 A nuestra clarificación conceptual nos ha ayudado: ARENDT, Hannah: Sobre la revolución, Madrid, Alianza Editorial, 1988, pp. 21-58; CASTELLS, Irene: La utopía insurreccional del liberalismo. Torrijos y las conspiraciones liberales de la década ominosa, Barcelona, Crítica, 1989, pp. 21-25; CEPEDA GÓMEZ, José: El ejército español en la política española (1787-1843). Conspiraciones y pronunciamientos en los comienzos de la España liberal, Madrid, Fundación Universitaria, 1990, pp. 172-176 y 266-280; DAVIDSON, Neil: Transformar el mundo. Revoluciones burguesas y revolución social. Barcelona, Pasado \& Presente, 2013, pp. 46-54; FLÓREZ, José Segundo: Espartero. Historia de su vida militar y politica y de los grandes sucesos contemporáneos, Madrid, W. Ayguals de Izcoz, 1844, vol. III, pp. 682-683; FUENTES, Juan Francisco y FERNÁNDEZ SEBASTIÁN, Javier: "Revolución” en Juan Francisco FUENTES y Javier FERNÁNDEZ SEBASTIÁN (dirs.): Diccionario politico y social del siglo XIX español, Madrid, Alianza Editorial, 2002, pp. 628-638; y MATTEUCCI, Nicola: Organización del poder y libertad. Historia del constitucionalismo moderno, Madrid, Editorial Trotta, 1998, pp. 128-143.
} 
Estatuto Real y radical Constitución de 1812. De otra parte, la más adelantada o integrista del doceañismo que, frente a ese carácter puramente instrumental conferido a ésta por los anteriores, le otorgaban, junto a la legislación con ella recuperada, otro valor, el del régimen alternativo al del Estatuto, limitando su reforma a lo estrictamente necesario.

La primera apadrinó y dominó las Cortes constituyentes que, buscando la conciliación con la Corona y la opinión conservadora y también presentarse como un partido respetable y responsable de gobierno, aprobaron la Constitución de 1837, que acogía el principio y la práctica política de la soberanía compartida y el bicameralismo, y las legislaciones políticas censitarias del régimen liberal representativo, electoral y de imprenta. La segunda se acantonó en el ámbito local urbano y resistió la transformación de las normativas de administración local y de la milicia nacional retomadas de la etapa de gobierno de los exaltados del trienio liberal, con el que quería enlazar y asentaba su ideario. De todas maneras, estas corrientes del progresismo, que perdurarían, confluirían para enfrentarse a los moderados que, cuando accedieron al poder con el respaldo de la Regente, no atendieron a esa transacción constitucional y propusieron otra desde la perspectiva reaccionaria del Estatuto ${ }^{2}$.

Para esta oposición progresista y para la conversión de Madrid en su ariete fueron fundamentales esos "últimos vestigios del doceañismo," principalmente la instrucción descentralizadora y democrática de régimen local de 3 de febrero de 1823. En primer término, esta normativa que, sustituyendo a la ordenación centralizada del tiempo del Estatuto, confería a los ayuntamientos y diputaciones unas atribuciones económico-administrativas propias y les permitía mantener comunicaciones directas con las instancias superiores. Pero también les ofrecía una importante intervención en el ámbito político-gubernativo, bien por la participación otorgada en la propia legislación de entonces (especialmente, electoral, de imprenta y de orden público) bien por la relación de cooperación y auxilio recíproco que les engarzaba con los delegados gubernativos, respectivamente, alcaldes y jefes políticos. El carácter democrático se perdió en las diputaciones, ya que al tener que ser nombradas por los mismos electores que los de los diputados a Cortes, se adecuaron al sistema electoral directo y censitario de la ley de 20 de julio de 1837 . No lo hicieron los ayuntamientos, que siguieron siendo elegidos, de acuerdo con la Constitución gaditana, mediante el sistema sufragio universal indirecto en un grado, incluido el alcalde, frente al régimen de las dos confianzas imperante bajo el Estatuto, y al jefe político, que le nombraba el gobierno.

La perduración de este rasgo democrático distanciaría política e ideológicamente a los ayuntamientos de las diputaciones. Así, en Madrid, donde invariablemente dominaron los progresistas, en la corporación provincial lo hicieron los de talante más

\footnotetext{
2 Para estas reflexiones: TOMÁS VILLARROYA, Joaquín: "Las reformas de la Constitución de 1812 en 1836", Revista del Instituto de Ciencias Sociales, 4 (1964), pp. 171-174 y 196-203; y de VARELA SUANZESCARPEGNA, Joaquín: "La Constitución de Cádiz y el liberalismo español del siglo XIX", Revista de las Cortes Generales, 10 (1987), pp. 69-90 y 94-107 (Reed. en Política y Constitución en España (1808-1978), Madrid, Centro de Estudios Políticos y Constitucionales, 2007); también nuestro trabajo, «El gobierno político de Madrid durante la última experiencia de la Constitución de 1812 (1836-1837)», Historia Constitucional, 12 (2011), http: www.historiaconstitucional.com. pp. 111-160.
} 
templado, mientras que en la municipal de la capital desde la primera elección de septiembre de 1836 el sector más avanzado sería el hegemónico. De esta manera el Ayuntamiento de Madrid, que hasta octubre de 1835 no había podido desprenderse de los regidores perpetuos y abrirse a la participación vecinal, y que durante la Monarquía del Estatuto siempre había estado rezagado ante las mudanzas políticas, bajo el régimen constitucional de 1837 adquirió una posición de vanguardia. Sería así porque, teniendo como todos los ayuntamientos un origen y carácter popular, sobresaldría por corresponder al mayor municipio y ser el de la capital del Estado.

Además, tanto en él como en la Diputación se encontraría la clave de la conversión de Madrid en el gran emblema del progresismo y desde finales de 1837 en la punta de lanza de la alternativa al cercano conservadurismo gobernante en las instituciones centrales de la Corte. Efectivamente, ambas corporaciones coadyuvarían sobremanera a que imperara y perdurara dicha opinión liberal. Primero, facilitando la difusión de su pensamiento en la prensa a través de la intervención, particularmente del Ayuntamiento, en la formación de los jurados. Así, a pesar de las restricciones paulatinamente introducidas en la libertad de imprenta, recuperada con la Constitución de Cádiz, esos tribunales populares no sólo se convirtieron en los principales garantes del libre ejercicio de ese derecho, sino que, con los moderados en el poder, serían un instrumento primordial para la acción de oposición progresista, al salvaguardar la continuidad del principal soporte de su opinión, el Eco del Comercio, y dar cobertura, dependiendo de la estrategia del momento, a publicaciones más radicales (El Guirigay, El Diablo Suelto, La Revolución, etc.).

Segundo, favoreciendo que la representación por Madrid en las Cortes correspondiera siempre al partido progresista. Así sucedería en todas y cada una de las elecciones legislativas desde 1836. Y, para ello, de una parte, las citadas corporaciones, con particular ventaja en este caso de la Diputación, pusieron a su servicio las amplias facultades conferidas por la norma electoral de 20 de julio de 1837: formación de las listas, fijación de los distritos, constitución de las mesas electorales y participación en la junta de escrutinio general. Lo hicieron, además, viéndose favorecidas y contribuyendo a la extensión del sufragio a las clases medias: se pasó de 267.290 electores en julio de 1837 a 461.593 en enero de 1840. De otra parte, bien involucrándose directamente en el desarrollo de la campaña de la mencionada formación política, bien optando sin ambages en los medios oficiales a favor de su candidatura. De esta manera, siendo la provincia de la capital de la Monarquía un lugar seguro para el progresismo, sus escaños en las Cortes fueron ocupados por las figuras estelares del partido (Agustín Argüelles, Joaquín María López, Fermín Caballero, Juan Álvarez Mendizábal...).

Tercero, integrándose con la prensa progresista en la labor de oposición parlamentaria al moderantismo gobernante. Así, la Diputación, pero llevando siempre la delantera el Ayuntamiento capitalino, participaron en esta tarea con las representaciones o exposiciones que elevaron a las instituciones centrales. Inicialmente, estarían restringidas a los aspectos que les afectaban más directamente, como eran los proyectos conservadores, que rebatieron, de recuperación del sistema de administración centralizado vigente bajo el Estatuto. Seguidamente, ya formarían parte de la acción y estrategia general de la oposición progresista, lo que les inmiscuiría en la situación 
política de momento, manifestando la desafección a un determinado ejecutivo conservador y a su política, solicitando la dimisión de un gobierno y/o la disolución de las Cortes, respaldando la actuación parlamentaria de los progresistas o defendido la Constitución y las libertades de las vulneraciones y contravenciones llevadas a cabo, a su juicio, por los moderados. Además, colaborarían alentando o no impidiendo las manifestaciones populares. En definitiva, la estrecha interrelación que se instauró entre los poderes locales, la prensa y la representación parlamentaria otorgaron al Madrid progresista una gran cohesión.

A este Madrid se sumó la milicia nacional. Lo hizo al seguir ordenándose por la reglamentación popular y democrática del trienio liberal, que, en cuanto también vestigio del doceañismo, facilitó su relación con el ayuntamiento, autoridad superior local, de la que dependía la organización, formación y funciones. Pero si este emparejamiento y los cometidos policiales municipales deslizaron al instituto hacia el liberalismo progresista, más aún lo promovió su objeto principal, la salvaguarda del régimen constitucional. Algo que alcanzó toda su dimensión en la situación que se vivía de guerra civil, haciendo persistir en la milicia el carácter de la expresión del antiguo derecho a la resistencia a la opresión o al despotismo y de defensa de la inacabada revolución liberal. Además, la involucración militar, que de aquí derivada, supuso un continuo crecimiento del número de efectivos -en Madrid se pasa de unos 4.000 milicianos en 1836 a más de 10.000 en 1840-y un permanente adoctrinamiento en un nacionalismo o patriotismo constitucional.

Esta identificación de la milicia con la nación liberal se produce en las celebraciones, sobre todo, por los éxitos y triunfos de las tropas isabelinas, pero también por los aniversarios del levantamiento contra los franceses del 2 de mayo (de 1808), de la Constitución de 1837 (18 de junio) y de la neutralización del golpe de estado absolutista del 7 de julio (de 1822). A pesar de su carácter estatal, de estos últimos estuvieron ausentes las autoridades centrales, siendo el ayuntamiento capitalino el que los organizó y convocó al vecindario a los actos festivos, en los que se afirmaron los principios de la nación liberal frente al carlismo: independencia y libertad, soberanía nacional y Constitución, derechos fundamentales y régimen representativo. En definitiva, todo señala que a la altura de 1840 gran parte del vecindario madrileño estaba ideológica y coactivamente bien pertrechado para hacer la revolución.

Algo que adquiere una trascendencia mayor en razón a la propia capitalidad y al ejemplo que ello conlleva, ya que la realidad descrita representa al otro Madrid, el de abajo y del ámbito local, diferente y alternativo al del poder central, al conservador de la Corte y del Gobierno. Corresponde a un nuevo Madrid, que quiere dejar de ser la tradicional "Villa y Corte" y de identificarse exclusivamente con la sede de la Monarquía y de las instituciones centrales, y transformarse en la capital de un Estado moderno con nuevas infraestructuras urbanas (asentadas en la desamortización y en la liberalización de la propiedad) e instituciones culturales, a la vez que metáfora o compendio de las virtudes de la nación de ciudadanos imaginada por el liberalismo progresista $^{3}$.

\footnotetext{
${ }^{3}$ Los distintos terrenos político-sociales los hemos explorado recurriendo primordialmente a: ARAQUE HONTANGAS, Natividad: Las elecciones en el reinado de Isabel II: la Cámara baja, Madrid, Congreso de
} 


\section{La defensa constitucional frente a la transacción conservadora}

Los moderados, ausentes de las Cortes Constituyentes, en términos generales no acogieron la transacción constitucional propuesta por los progresistas con el Código político de 1837. Parece que, principalmente, la penetración de la misma en sus filas provino ante todo de disidencias por la derecha del progresismo. Por eso, a su alumbramiento, un sector de la prensa conservadora lo recibió cuestionando su legitimidad como un "producto del movimiento sedicioso de La Granja" y recordó con añoranza el régimen estatutario precedente. $Y$ es que, a pesar de asentar su estructura política en presupuestos doctrinarios, a los moderados les resultaba insuficiente, y la parte dogmática excesivamente radical.

De esta forma, desde el inicio de este régimen el ala retrograda de este partido, los estatuistas o jovellanistas, reclamó la necesidad de una contrarreforma. Pues bien, este grupo, con gran predicamento e influencia en la Corte, tuvo mucho que ver con el acuerdo matrimonial borbónico propuesto al tiempo de la expedición real, que resultó fallido, y con la instauración de los gobiernos de los realistas moderados, conde de Ofalia y duque de Frías. Así, paulatinamente, penetrando en las esferas gubernativas, se fue abriendo camino la idea de "otra transacción" con las monarquías orleanista francesa y carlista, y sus presupuestos tradicionales.

Esta transacción conservadora acabó sustituyendo en el lenguaje a la anterior progresista, hasta el punto de verse desterrado el término del vocabulario de este grupo liberal, y calificar a aquella de funesta o abominable. Además, sirvió, como ya hemos indicado, para aunar las filas de este partido en torno al texto del 37 y a la exigencia de su completa y fiel observancia, renunciando los más radicales en un principio a la profundización más democrática del régimen y asumiendo los más rezagados, sus artífices principales, una lectura parlamentaria.

Antagónicamente pensaban los moderados. Era el sentido monárquico el que debía imperar en la interpretación y el desarrollo constitucional, reclamaba con ahínco la publicación reaccionaria Revista de Madrid. Su expresión más palmaria se pudo constatar en el verano de 1839 cuando, una vez lograda la cohesión interna en el partido, el Gobierno de Evaristo Pérez de Castro, a pesar del triunfo abrumador de los progresistas en las elecciones legislativas de agosto, se mantuvo en el poder sostenido exclusivamente por la confianza regia. Más aún, aduciendo que no se había podido consultar el cambio de opinión operado tras la conclusión de la guerra las provincias vascas con el convenio de Vergara, la Regente le concedió el decreto de disolución. Obviamente, lo que se pretendía, con la mayoría que se esperaba alcanzar en los comicios convocados para enero de 1840 era robustecer y fortalecer la autori-

los Diputados, 2008, pp. 115-248; BAKER, Edward: Materiales para escribir Madrid. Literatura y espacio urbano de Moratín a Galdós, Madrid, Siglo XXI, 1991, pp. 74-82; CASTRO, Concepción: La Revolución Liberal y los municipios españoles (1812-1868), Madrid, Alianza Editorial, 1979, pp. 121-166; CASTRO ALFÍN, Demetrio: Los males de la imprenta. Política y libertad de prensa en una sociedad dual, Madrid, Centro de Investigaciones Sociológicas, 1998, pp.39-50; PÉREZ GARZÓN, Sisinio: Milicia Nacional y Revolución burguesa. El prototipo madrileño, 1808-1874, Madrid, Consejo Superior de Investigaciones Científicas, 1978, pp. 409-478; SERRANO, Carlos: El nacimiento de Carmen. Símbolos mitos y nación, Madrid, Taurus, 1999, pp. 161-171. 
dad de la Corona, mediante las reformas propuestas centralizadora de la normativas referidas a la organización y atribuciones de ayuntamientos y diputaciones, censitaria de la electoral, censoria de la de libertad de imprenta y restrictiva de la de milicia nacional para que el gobierno y la administración estuvieran en consonancia con la Constitución, entendida, eso sí, en un sentido monárquico o desde una visión cercana al Estatuto.

Este modelo conservador de Monarquía constitucional suponía no sólo excluir a los progresistas como partido de gobierno, sino eliminarles como potencial alternativa política, ya que lo que se buscaba era desplazarles de las instancias como los ayuntamientos, diputaciones, milicia nacional o prensa donde eran hegemónicos. Particularmente de la provincia y villa de Madrid, el caso, como hemos visto, más paradigmático ${ }^{4}$.

Pues bien, siguió ocupando esta posición de vanguardia, como se puso de manifiesto en las elecciones. Así, si para el triunfo generalizado de los moderados resultó básica la potenciación del jefe político, para que en la provincia de la Corte mantuvieran su dominio los progresistas lo fue la del Ayuntamiento de la capital. En el primer caso se recuperaron para el delegado gubernativo alguno de los perfiles del gobernador civil de la época del Estatuto, como el control previo de la circulación de la prensa, que le confirió la orden de 5 de junio de 1839 contraviniendo el derecho de libertad de imprenta, o el control del proceso electoral, que le otorgaron las órdenes de 6 de diciembre y 8 de enero de 1840, usurpando las atribuciones concedidas a las diputaciones por la ley electoral. Frente a esta transformación del jefe político en agente electoral del partido ministerial, en el segundo caso se afirmó a la corporación municipal capitalina como la institución central de los progresistas, al colocar al frente de las alcaldías, tras los concurridos comicios municipales de finales del 39, a los principales líderes del partido, con Salustiano Olózaga a la cabeza.

Desde aquí, en primer lugar, se contrarrestó la intervención gubernativa en las elecciones y, participando en la candidatura progresista, se logró siguiera siendo la que triunfara a Madrid. En segundo lugar, se sumó a la exigua representación progresista del Congreso y a la prensa ideológicamente afín en la campaña de denuncia del generalizado fraude electoral. En tercer lugar, dio cobertura a las manifestaciones y algaradas populares contra la mayoría moderada promovidas a la inauguración de la legislatura. En cuarto lugar, resistió al estado de sitio declarado en Madrid el 24 de febrero para impedir la prolongación de las anteriores movilizaciones. En definitiva, el Ayuntamiento de la capital se convirtió en el adalid de la resistencia al poder de los conservadores.

4 Al respecto, ARTOLA GALLEGO, Miguel: La burguesía revolucionaria (1808-1874), Madrid, Alianza Editorial, 1990, pp. 140-142, BURDIEL, Isabel: Isabel II. Una biografia (1830-1904), Madrid, Taurus, 2010, pp. 48-60; MARCUELLO BENEDICTO, Juan Ignacio: La práctica parlamentaria en el reinado de Isabel II, Madrid, Congreso de los Diputados, 1986, pp. 203-207 y 300-309; MARICHAL, Carlos: La revolución liberal y los primeros partidos políticos en España: 1834-1844, Madrid, Ed. Cátedra, 1980, pp. 185-191; y Revista de Madrid I (1840), Crónica del mes de enero. También nuestro trabajo "La regente María Cristina en el verano de 1837: entre la ciudad amenazada y la ciudad clandestina", en Encarna GARCÍA MONERRIS, Mónica MORENO SECO y Juan I. MARCUELLO BENEDICTO (eds.): Culturas politicas en la España liberal. Discursos, representaciones y prácticas (1808-1902), Valencia, Publicacions de la Universitat de Valencia, 2013, pp. 103-108. 
De esta manera Madrid se presentaba para los moderados como el ejemplo más genuino de la aplicación práctica de la instrucción de 3 de febrero de 1823, que calificaban de "anárquica y federalista" y propia de un régimen republicano porque consideraban otorgaba a las corporaciones locales tan desmedida independencia y discrecionalidad, que "rayaba casi es una especie de soberanía." Y por eso también la urgente necesidad de su sustitución por otra que, para que fuera conforme a una "Monarquía constitucional bien construida" y permitiera al Gobierno ejercer plenamente sus facultades, debía seguir, según los conservadores, el modelo de administración territorial estrictamente centralizado francés. A él correspondía el proyecto de organización y atribuciones de los ayuntamientos presentado en las Cortes, que los reducía a simples partes de la administración del Estado y puros cuerpos consultivos del alcalde que, en calidad de delegado gubernativo, volvía a sustentarse en el sistema de las dos confianzas, mientras los demás miembros eran elegidos por un restrictivo sufragio censitario.

Aunque los diputados progresistas desde la tribuna del Congreso reprobaron este proyecto por considerarlo contrario tanto al espíritu como a la letra de la Constitución, particularmente el aspecto referido a la elección mixta del alcalde, sin embargo la oposición más contundente se produjo fuera del hemiciclo. Y es que el debate parlamentario volvió a evidenciar la división de los progresistas: los rezagados que, dominando en la representación parlamentaria, al discrepar de la propuesta municipal moderada no lo hicieron desde la defensa de la legislación de 1823, porque la estimaban radical y desacorde con la Constitución vigente; y los avanzados que, copando los principales ayuntamientos, desde una lectura doceañista de ésta consideraban a la ordenación local imperante no sólo plenamente ajustada sino alternativa al modelo centralizador de los moderados.

De todas formas, en un primer momento, eso sí muy corto, llevaron la iniciativa los primeros. Fue así porque el apoyo a las demandas de los progresistas realizado por el hombre más influyente del momento, el general Baldomero Espartero, reconocido entonces como duque de la Victoria, debía cuidarse y esto implicaba situarse en el espectro ideológico liberal bastante contenido que profesaba. Tanto más cuanto a través de su ascendencia en el Palacio Real hasta abril los progresistas no perdieron definitivamente la esperanza de verse reintegrados al área de gobierno. Confirmada entonces la hoja política de ruta de los moderados con María Cristina a la cabeza, no tenía sentido alguno contener el discurso radical del partido. Más bien al contrario, era necesario difundirlo para lograr apoyos en la base social.

Eso es lo que hizo el Ayuntamiento de Madrid, reafirmado en el progresismo avanzado con el paso de alguno de los alcaldes a los escaños conseguidos en el Congreso y sustitución por otros como Joaquín María Ferrer, que asumió la vara de primer munícipe, y Joaquín María López. Éste fue el que se encargó de la redacción de la exposición que, como otras muchas corporaciones locales, la de la capital elevó a las Cortes solicitando la retirada del proyecto municipal conservador y, recuperando para la realidad local un historicismo liberal muy doceañista, el mantenimiento de la instrucción de 1823.

A partir de aquí, desde la posición nuclear en la formación de los jurados, el Ayuntamiento facilitó el desarrollo de una campaña de prensa muy agresiva contra el par- 
tido moderado y su propuesta municipal, cuyo espectro ideológico se amplió a los periódicos republicanos y demócratas (La Revolución, El Huracán), lo que no pudo que por menos de exasperar al Gobierno y reafirmarle en sus reformas legislativas ${ }^{5}$. Pero fue bastante más lejos al participar en la formación de un discurso radical, fundado en una lectura parlamentaria de la Constitución vigente, en el recurso a la vía insurreccional para su defensa y el ejemplo de la jornada de 7 de julio de 1822 . Y al movilizar bajo esta bandera a la ciudadanía, particularmente a la milicia nacional.

Para ello se recurrió, como era habitual, a los homenajes y celebraciones oficiales. El acto celebrado por la milicia madrileña con ocasión del triunfo de Morella y también por el nombramiento del general esparterista Valentín Ferraz como inspector general del cuerpo miliciano destacó por el carácter asambleario de la reunión realizada en la sala de columnas del Ayuntamiento, por la patente adhesión a ese discurso radical ("tal vez se aproxima el tiempo de que los que suscriben hayan de hacer con el fusil lo que hoy dicen con la pluma") y porque la felicitación a Baldomero Espartero y su ejército fue una excusa para solicitar su apoyo en defensa de la Constitución y la libertad que, a su juicio, estaban siendo ultrajadas por el Gobierno y la Cortes moderadas. Este mismo leitmotiv fue el de la conmemoración del aniversario de la Constitución, pero sobre todo del de "la memoria de los héroes del 7 de julio de 1822," en la que el Ayuntamiento volcó sus mayores esfuerzos y se otorgó un protagonismo principal a la milicia nacional. El programa constó de un recorrido por los lugares de los enfrentamientos más notables de 1822, un desfile de gala por las calles adyacentes a la Casa Consistorial para colocar una lápida conmemorativa en el arco de la calle de Siete de julio que da acceso a la Plaza Mayor (entonces de la Constitución), una sesión pública y extraordinaria de la corporación municipal para rendir homenaje a los milicianos de entonces y, engalanada la Casa de la Panadería, la animación en dicha plaza con himnos patrióticos y bailes nacionales a cargo de las bandas de música de la milicia. Durante esta jornada se difundió profusamente un bando del Ayuntamiento, en el que se hacía una interpretación doceañista de la vigente Constitución y realizaba una suerte de identificación entre la situación que se vivía y la de 1822, animando a los milicianos a que imitaran el ejemplo de los Héroes del 7 de julio en defensa de la libertad.

\footnotetext{
5 Para el contexto hemos seguido a: ALCALÁ GALIANO, Antonio, Historia de las Regencias (18331843). Continuación de la historia de España de S.A. Dunham, Madrid, Imprenta y Sociedad Literaria y Tipográfica, 1844-1846. (Reed. Pamplona, Urgoiti, Editores, 2008), pp. 224-239; FLÓREZ, José Segundo: Espartero... vol. III, pp. 188-231; y RICO AMAT, Juan: Historia política y parlamentaria de España (desde los tiempos primitivos hasta nuestros días), Madrid, Imprenta de las Escuelas Pías, 1861, vol. III, pp. 216235. Para las elecciones: ARAQUE HONTANGAS, Natividad: Las elecciones en el reinado...pp. 215-248; y JANKE, Peter: Mendizábal y la instauración de la Monarquía constitucional en España (1790-1853), Madrid, Siglo XXI, 1974, pp. 294-307. Para la prensa CASTRO ALFÍN, Demetrio: Los males de la imprenta ...pp.4450. Para las distintas visiones de la normativa local de 1823: DÍAZ, Nicomedes Pastor: "La cuestión electoral en diciembre de 1839 y enero de 1840," en Obras completas de..., Madrid, Atlas, 1970, vol. II (Biblioteca de Autores Españoles, núm. 228), pp. 9-33; CASTRO, Concepción: La Revolución..., pp. 154-160; y nuestro trabajo "Los debates parlamentarios de la ley municipal de 1840," Revista de Estudios Políticos 93 (1996), pp. 273-290. Y para la respuesta progresista y del Ayuntamiento de Madrid a la reacción conservadora: Archivo Real Academia de la Historia (en adelante, A. R. A. H.), Archivo particular de Isabel II, serie $1^{\mathrm{a}}$, legs. 8 ( $2^{\mathrm{a}}$ parte) partes del jefe político de Madrid al ministro de la Gobernación y de policía a la regente firmados por C. F. (1840); Archivo Villa de Madrid (en adelante A. V. M.), Secretaría, 1/224/124, 1/227/36 y 4/163/6.
} 
Con este homenaje, llevado a cabo con un particular esmero, se quería patentizar que el Madrid progresista estaba dispuesto a resistir cualquier vulneración constitucional. Pero también se pretendía, una vez que como era de esperar tuviera éxito la insubordinación, sino retrotraerse al momento pre-constituyente de 1836, si al menos realizar una lectura más avanzada del texto constitucional de acuerdo con el imaginario liberal-democrático que acompañaba a ese episodio heroico del trienio y que, en alguna medida, entonces estaba siendo una realidad en Madrid. Los aniversarios, la milicia ciudadana, la prensa popular, el Ayuntamiento elegido por todos los vecinos y sus sesiones públicas eran elementos que debían preservarse porque no sólo, desde una perspectiva democrática, extendían y ampliaban las posibilidades de participación en el ámbito público, sino también expandían la libertad, ideal del liberalismo, ya que, como subrayaba el Eco del Comercio, "la libertad es alegre y bulliciosa, amiga de funciones cívicas y de reuniones numerosas; de esto vive y, cuando este síntoma de espíritu público muere en un pueblo, muy cerca está de su esclavitud ${ }^{6}$."

\section{Preparativos para la insurrección}

La sanción real el 14 de julio de la normativa municipal aprobada por las Cortes, considerada la expresión de la definitiva conculcación del texto constitucional, fue contemplada como una especie de carta blanca para proceder al ejercicio del derecho a la resistencia. Lo favorecía, de una parte, la sensación de vacío de poder que se vivía en Madrid por el traslado a Barcelona de la familia real y de una parte importante del gabinete. De otra parte, también alentaba la insubordinación, el compromiso ya del general Baldomero Espartero con el programa básico de los progresistas. Así lo hizo al presentar la disolución de las Cortes y la retirada del proyecto municipal como condiciones inexcusables para atender al ofrecimiento de formación de gobierno planteado por la regente. La citada sanción realizada por ésta y la dimisión de todos cargos presentada por aquel, y no aceptada, cerró el primer pulso en las altas esferas del Estado y desembocó en los disturbios de los días siguientes de la ciudad condal.

En ellos, con el beneplácito del Ayuntamiento, fueron los protagonistas paisanos y milicianos nacionales, se aclamó la Constitución y al duque de la Victoria y vituperó al Gobierno y al proyecto municipal, se formaron barricadas y acopiaron armas, se produjeron algunos asesinatos aislados y se destruyó la imprenta de El Guardia Nacional. El ejército no reprimió a los sublevados y fueron los llamamientos de ese general y, sobre todo, la constitución el 20 de julio del nuevo gabinete presidido por el esparterista y progresista Antonio González los que lograron tranquilizar los ánimos.

6 Para el desarrollo y valor de esta celebración. A. V. M., Secretaría, 2/415/60 y 3/322/8 y libros de acuerdos del Ayuntamiento, núm. 275, sesión de 7 de julio de 1840; Eco del Comercio, 5,7 y 8 de julio de 1840, núm. 2.257, 2.259 y 2.260; Revista de Madrid, I (1840), crónica del mes de julio, p. 280. En cuanto a la bibliografía: ALCALÁ GALIANO, Antonio: Historia de las Regencias..., pp.244-245; NIDO SEGALERVA, Juan: Historia política y parlamentaria de S. A. D. Baldomero Fernández Espartero, Madrid, Imp. de Ramona Velasco, 1916, pp. 360-361; y ROMEO MATEO, María Cruz:'Los mundos posibles del liberalismo progresista”, en Emilio LA PARRA y Germán RAMÍREZ: El primer liberalismo: España y Europa, una perspectiva comparada, Foro de debate, Valencia, 25 a 27 de octubre de 2001, Valencia, Biblioteca Valenciana, 2003 pp. 299-308. 
Las noticias imprecisas recibidas en Madrid sobre estos confusos acontecimientos generaron cierto desconcierto. Por de pronto, en el Congreso abarrotado de gente, los diputados de la mayoría moderada, ante la falta de información gubernativa alguna "acerca del estado de los negocios públicos" y la situación comprometida en que les colocaba el nuevo ejecutivo progresista, el 24 de julio acordaron suspender las sesiones. Al día siguiente hizo lo propio el jefe político, Diego Entrena, pero, al no aceptar la resignación de su cargo ni el intendente ni el secretario del Gobierno político, acumuló la responsabilidad el gobernador militar José Clemente Buerens.

En estas circunstancias, de oscura transición de autoridades y de incertidumbre sobre el devenir del sancionado, pero no publicado, proyecto municipal moderado, era razonable que entre los madrileños reinara el desasosiego, que grupos de vecinos se congregaran en la Puerta del Sol y que algunos de ellos, un tanto desorientados, quisieran imitar a los sublevados de Barcelona. Lo hicieron, con escaso acierto, el 27 de julio: por la mañana, asaltando la redacción del diario conservador El Correo Nacional, llevándose alguno de sus ejemplares para después quemarlos en la citada plaza; y, por la tarde, juntándose en la del Senado, para protestar por los sucesos de la ciudad condal ante los miembros de esta cámara que, habiendo sido convocados, no acudieron. Fueron patrullas de la milicia y del ejército las que se encargaron de sofocar los disturbios.

Todo indica que, para evitar este tipo de derivas, el Ayuntamiento capitalino decidió tomar la iniciativa. Así, el 31 de julio agradeció a la homónima corporación barcelonesa por los eminentes servicios prestados en defensa de los derechos constitucionales y al general Baldomero Espartero por la conclusión de la guerra. En la exposición a este general se subrayaba, ante todo, el triunfo del régimen liberal, de los derechos del pueblo y el trono de Isabel II, y se confundía su actuación militar con la política, particularmente la realizada últimamente a favor de la "inmunidad de la Constitución." Además, se acordó obsequiarle con una pequeña escultura, celebrar a su regreso a la capital tres días de festejos en su honor y comisionar al alcalde segundo, Francisco Javier Ferro Montaos, para felicitar a la regente por la terminación del conflicto y al duque de la Victoria también "por su honrosa decisión en defensa de la Constitución e independencia nacional." Y, por último, quizás lo más importante, se logró que la milicia nacional realizara un gesto similar, no como cuerpo, pero sí por medio de representaciones particulares de cada uno de los batallones, en las que, al tiempo, expresaban su compromiso con esos grandes valores.

Estrechados de esta manera los lazos entre y con la milicia, el paso siguiente del Ayuntamiento fue sumar a la distanciada Diputación y a las grandes figuras del partido progresista que, cercanas en su mayoría al sector rezagado, con la terminación del debate del proyecto municipal se encontraban un tanto dispersas. Para ello se recurrió al vocal progresista avanzado de aquella, Pedro Beroquí, a la tertulia del 18 de junio, creada bajo su inspiración para difundir la interpretación liberal y parlamentaria de la Constitución, y al periódico con idéntico ideario dirigido por José García Villalta, El Labriego. El resultado fue la Asociación Patriótica Constitucional de la provincia de Madrid, que inició su andadura el 15 de agosto. Tenía por objeto la defensa de la Constitución y las leyes, y se organizaba siguiendo la estructura que se habían dotado los progresistas para las elecciones legislativas; es decir, contaba con una dirección 
que, residenciada en una junta provincial, se renovaba anualmente y establecía a partir de las juntas elegidas por los socios en las secciones formadas por los distritos electorales. Pero, al tiempo que enlazaba con las sociedades patrióticas del trienio, esta asociación iba más lejos, anticipándose a los partidos políticos modernos, ya que, por su carácter de organización permanente, sus miembros debían pagar una cuota (se eximía a los jornaleros y a los socios que carecieran de recursos), y también porque formaba una comunidad que "protegía a sus individuos, ya fuera pecuniariamente, ya ante los tribunales o de cualquier otro modo, en las persecuciones políticas que pudieran sobrevenirles por causas políticas."

Esta asociación, en cuya primera junta estarían, entre otros, Ramón María Llopart, en calidad de presidente, y los citados, Pedro Beroqui y José García Villalta, contó como vocales con ilustres socios como Ramón Gil de la Cuadra, Valentín Llanos, Agustín Argüelles, Evaristo San Miguel, Manuel Cortina, el marqués de Peñaflorida.... Desde su comienzo José Clemente Buerens tuvo hacia ella una gran prevención porque consideraba se había creado sin autorización gubernativa y llamaba a todas las clases, y porque le parecía que para la defensa de la Constitución "los españoles no necesitaban asociarse revolucionariamente." Contando con más información, este jefe político otorgó al Ayuntamiento una notable influencia en su creación y le confirió las tareas de integración del partido del progreso y de formación de la opinión y del discurso del cambio político.

En el mismo ideario de esta Asociación Patriótica Constitucional se encuadraba el programa que Antonio González, contando con el beneplácito del general Baldomero Espartero, había presentado a la regente el 9 de agosto. En él se recogían las consabidas demandas de suspensión de la promulgación y ejecución de la ley de ayuntamientos, y de disolución y convocatoria de nuevas Cortes. También se planteaba impulsar la regeneración política que, basada en una lectura avanzada de la Carta Magna, daba entrada a un modelo de Monarquía parlamentaria, asentada en "la rígida observancia de los principios del régimen representativo" y del Estado de Derecho, y en la ampliación de las funciones del consejo de ministros en detrimento del monarca.

María Cristina rechazó esta transformación política y Antonio González dimitió, no así los demás compañeros de gabinete que, bajo la presidencia del también esparterista Valentín Ferraz, el 12 de agosto formaron un nuevo Gobierno, sin definición política alguna. Para complicar aún más la situación, acompañando a la familia real se trasladó a Valencia. En definitiva, un proceso de descomposición ministerial y de vacío de poder cada vez más evidente, ante los que el Ayuntamiento madrileño trató de responder. Así, en la sesión del martes 18 de agosto, con una importante agitación popular tanto dentro como fuera de la Casa Consistorial, después de un intenso debate, se decidió por unanimidad asumir como pauta de actuación el principio lockiano de "resistencia legal contra todas las medidas contrarias al espíritu y a la letra de la Constitución."

Este acuerdo acabó suponiendo que, considerado legítimo el ejercicio del derecho a la resistencia frente a la arbitrariedad del poder, el Ayuntamiento aceptaba liderar su aplicación tanto a nivel de la capital y provincia madrileñas como a nivel nacional. Pero, para dar cualquier paso, era imprescindible contar con la "cooperación de los ciudadanos armados" y el apoyo popular. Los primeros se adhirieron en las 
asambleas celebradas en los distintos batallones, a las que agregaron las reuniones efectuadas entre los concejales y los oficiales de milicia, en las que se distribuyeron los diferentes papeles en la trama insurreccional. El segundo, el respaldo ciudadano, se logró a través de los diferentes encuentros mantenidos por los alcaldes con los vecinos de los distritos y, sobre todo, por el medio que se evidenció más importante para activar su movilización, las sesiones municipales públicas de los martes. En ellas, recordaba Antonio Alcalá Galiano, se concedía a los asistentes "el derecho de hablar en los negocios que se trataban, ni más ni menos que los mismos concejales," y se debatía sobre cuestiones políticas "como si fuesen de su competencia;" si bien, significaba Juan Nido Segalerva, los concejales, periodistas y notables del partido progresista llevaban la voz cantante. Así sucedió en la sesión anteriormente citada y también en la del 25 de agosto, acabando por convertir a esta asamblea pública municipal en la instancia decisoria del proceso insurreccional madrileño. Con ello las potencialidades democratizadoras de la normativa de 1823 alcanzaban la máxima expresión, acercándose a la versión que sobre la misma sustentaban los conservadores.

Junto a estos "Congresos populares" hubo otras reuniones secretas, llevadas a cabo por miembros del Ayuntamiento, según la policía, en calidad de "club director de la Corte." En ellas, dando cabida a destacados miembros de partido progresista vinculados a la Asociación Patriótica Constitucional, se diseñó, de acuerdo con la información gubernativa, la "organización de la revolución." Tanto de Madrid, distribuyendo el despliegue de las fuerzas armadas, como de las provincias, fijando los pasos a seguir en unas instrucciones que, distintos comisionados podrían en manos de los ayuntamientos de la capitales para que, a imitación del de la Corte, se pusieran a la cabeza de la movilización. De estas reuniones clandestinas, los jefes políticos, particularmente el de Madrid, supieron que una importante "parte del ejército sostendría el pronunciamiento" y que, aunque se contaba con el apoyo del duque de la Victoria, siempre era necesario buscar su beneplácito.

Así las cosas, la serenata que, a su regreso a la capital, se había programado dar a Antonio González, héroe popular del momento, hizo saltar todas las alarmas en la sede de Gobierno Político porque se temía fuera la ocasión para precipitar la insurrección. Por eso José Clemente Buerens solicitó a Joaquín María Ferrer, alcalde de la capital, que denegara el permiso y tomara las oportunas medidas para la conservación del orden. No hizo ni lo uno ni otro porque, para él y los que estaban en el señalado club director, era una oportunidad para evaluar los distintos comportamientos ante el proyectado pronunciamiento. Así, pudieron constatar que las fuerzas policiales, los salvaguardias, desplegadas por el jefe político eran fácilmente neutralizables. También que, en la serenata realizada en la noche del 29 de agosto en la Plazuela de Santa Ana, los milicianos que la habían organizado lograban congregar a una importante multitud, que se conducía dentro de unos cauces de gran normalidad, dando los esperados vítores a favor de la Constitución, de Antonio González y su programa de gobierno, y en contra de los "traidores y apóstatas?."

\footnotetext{
7 Para estos cambios políticos y la reacción en Madrid las fuentes a las que hemos recurrido han sido: Archivo General Palacio (en adelante A. G. P.), Reinados, Fernando VII, 15/7, 9, 11,12, 15 y 16 , y $17 / 8$ y 9 informes policiales y del jefe político de Madrid a la regente, julio y agosto de 1840, A. R. A. H., Archivo particular de Isabel II, serie $1^{\mathrm{a}}$, legs. 8 ( $1^{\mathrm{a}}$ parte); bases o programa del Ministerio de Antonio González; A.
} 


\section{El glorioso pronunciamiento}

Pues bien, el gentío que se juntó en la siguiente sesión pública de los martes, la del 1 de septiembre, creció sobremanera, ocupando no sólo el salón consistorial, sino la Plaza de la Villa y la Puerta del Sol. Para entonces ya se tenía noticia del nombramiento el 28 de agosto del nuevo Gobierno moderado presidido por Modesto Cortázar, que era contemplado como la recuperación del reaccionarismo y de la inmediata promulgación de la ley municipal. Por ello, los congregados estaban sobreexcitados y el Ayuntamiento atendió a sus requerimientos en defensa de "la libertad y de la Constitución" amenazadas, en lugar de a los del jefe político en pos del mantenimiento del orden público, poniendo sobre las armas a la milicia nacional y ordenando el toque de generala. De esta manera, colocándose al frente del pronunciamiento proyectado, la corporación municipal reunida en sesión permanente acordaba: comunicárselo para su conocimiento a la Regente y al general Baldomero Espartero, y para su adhesión a los ayuntamientos de las capitales de provincia; poner bajo control las puertas de la capital y distribuir armas entre "los vecinos honrados de opinión liberal," e impeler a todas las autoridades a su supeditación, y emitir un bando en el que se presentaba la insubordinación popular como respuesta al "ominoso sistema de reacción" imperante. Seguidamente, trasladada a la Casa de la Panadería, y reunida con la Diputación provincial y los comandantes de los cuerpos de la milicia, constituyeron una Junta provisional de gobierno de la provincia de Madrid formada con miembros del sector avanzado del progresismo. Así, presidida por el primer munícipe madrileño Joaquín María Ferrer, tendría como vocales, también del Ayuntamiento de la capital, a los alcaldes Pío Laborda y José Portilla, al regidor Valentín Llanos, y al procurador síndico Fernando Corradi, que haría las veces de secretario, y de la Diputación provincial a Pedro Beroqui y Pedro Sainz de Baranda.

La primera de las medidas de esta Junta fue el reemplazo el 2 de septiembre de las autoridades civiles y militares contrarias a la insurrección por otras de su mismo talante. José Clemente Buerens, detenido por oponerse a la movilización de la milicia, fue sustituido interinamente en el cargo de jefe político por Juan Lasaña Mathe, alcalde que fue de Madrid después del levantamiento del verano de 1836 y a continuación ininterrumpidamente diputado a Cortes. Al frente del Gobierno militar, y asumiendo también interinamente las funciones de inspector de la milicia nacional, se sitúo al

\footnotetext{
V. M., Secretaría, 1/225/18, 27 y 30, 3/370/15 y libros de acuerdos del Ayuntamiento, núm. 275, sesiones de 18, 24, 28 de julio y 6,11, 18 y 25 de agosto de 1840; Diario de sesiones de Cortes (en adelante, D. S. C.) (Congreso), sesiones del 18, 24 de julio de 1840, núm. 131, 136, pp. 3.348-3.354 y 3.487-3.489; Boletín Oficial de Madrid, 28 de julio de 1840, núm. 1.183; Diario de Madrid, 19 y 20 de julio de 1840, núm. 1.941 y 1.942; El Correo Nacional, 19, 21 y 29 de julio, y 26 y 30 de agosto de 1840, núm. 912, 914, 922, 950 y 954; Eco del Comercio, 19 y 21 de julio y 2,12, 18, 22 y 23 de agosto de 1840, núm. 2.271, 2.277, 2.285, 2.285, 2.295, 2.301, 2.305 y 2.306; Revista de Madrid, I (1840), crónica del mes de julio, pp. 270-286. En cuanto a la bibliografía: ALCALÁ GALIANO, Antonio: Historia de las Regencias... pp. 244-255; ARTOLA GALLEGO, Miguel: La burguesía...pp. 143; BURDIEL, Isabel: Isabel II....pp. 58-65; NIDO SEGALERVA, Juan: Historia política pp. 363-366; y PIRALA CRIADO, Antonio: Historia de la guerra civil y de los partidos liberal y carlista. Refundida y aumentada con la historia de la Regencia de Espartero, Madrid, Turner-Historia 16,1984, vol. VI, pp. 132-165; y Reseña histórica del glorioso alzamiento de 1840, Madrid, V. Lalama, 1840, pp. 3-19.
} 
mariscal de campo ayacucho Narciso López Oriola. Ideológicamente algo más avanzado era Antonio Tomé y Ondarreta, que asumió el puesto de subinspector del cuerpo de la milicia, y del mismo talante progresista templado Ramón María Calatrava Peinado, que aceptó hacerse cargo interinamente de la gestión de la Intendencia.

El capitán general del distrito, Juan Antonio Aldama, dirigió la oposición armada al pronunciamiento, que fue fácilmente repelida porque, acantonado momentáneamente en el Retiro, gran parte de los efectivos a su mando se sumaron a los sublevados; de la misma manera que los hicieron los del cuerpo policial de los salvaguardias. Pues bien, para la organización de la defensa armada fue nombrado, sustituyendo al anterior, el general también ayacucho, José Ramón Rodil Pampillo. Así a su iniciativa se debieron las disposiciones de la Junta declarando el armamento general de los madrileños y decidiendo proceder a la construcción de algunas fortificaciones. A estas medidas se sumó la distribución en la capital de los milicianos nacionales de los pueblos limítrofes y de las tropas del ejército acantonadas en otros lugares de la provincia, que harían que la fuerza armada con que contara casi desde el principio el Madrid insubordinado se situara en torno a los 20.000 hombres.

En esta protección armada se asentó la exposición que la Junta elevó a la regente el 4 de septiembre, considerada después bandera y programa político del pronunciamiento. En ella se legitimaba la insurrección en razón al abuso del poder, a la vulneración de los principios del sistema representativo y a las permanentes agresiones a la Carta Magna. Se reclamaba, además de la suspensión de la ley municipal y la disolución de las Cortes, el nombramiento de un nuevo Gobierno "compuesto de hombres decididos" y la exigencia de responsabilidad de los anteriores ejecutivos conservadores. La respuesta del último gabinete de este talante, minusvalorando los apoyos a la insurrección madrileña porque, esgrimiendo falsos pretextos - decía- se había "enarbolado la bandera de la revolución" y advirtiendo que se habían adoptado las disposiciones más enérgicas y eficaces para el restablecimiento del orden, fue fácilmente contrarrestada. De una parte, por la imitación y agregación sucesiva al pronunciamiento de las principales capitales de provincia. De otra parte, y decisivamente, por el franco compromiso del general Baldomero Espartero con los insubordinados que, liderados -señalaba- por "el partido liberal llamado del progreso," los presentaba a María Cristina como los auténticos garantes de su Regencia, del trono de Isabel II, de la Constitución del Estado y de la independencia nacional.

Con este importante respaldo la Junta recibía un reconocimiento cuasi oficial y podía seguir adelante con una mayor seguridad. Así, para consolidar la insurrección puso bajo su control a la Imprenta Nacional y la Gaceta de Madrid se convirtió en su principal medio de comunicación. Procedió a crear comisiones específicas de hacienda y de guerra. La primera fue la que gestionó la firma de un préstamo de un millón de reales, imprescindible para que la segunda pudiera abastecer a la infinitud de uniformados, que no dejaban de llegar y hacían que Madrid ofreciera el aspecto de un campamento militar.

En el ámbito de la seguridad pública, puesto bajo la autoridad del jefe político, por un lado, se encargó al Ayuntamiento potenciar en los diez distritos de la capital comisiones de vigilancia presididas por un regidor y contando con los alcaldes de barrio y, por otro lado, se contó con el cuerpo de salvaguardias. Este entramado policial, 
entre cuyos distintos componentes Juan Lasaña, queriendo olvidar antiguas rencillas, buscó que imperara la buena armonía al estar "enlazados -subrayaba- por identidad de ideas y de principios", debía controlar y evitar la fuga de los "enemigos del noble y patriótico pronunciamiento."

¿Quiénes eran éstos? Al margen de los carlistas, que acababan de ser derrotados, los mayores adversarios eran los miembros del Gobierno de Evaristo Pérez de Castro, para quienes la Junta de Madrid dictó una orden de detención. Seguidamente los nombres más destacados del partido moderado y su principal órgano de prensa $E l$ Correo Nacional que, por violentas intimidaciones, no pudo publicarse entre el 2 y el 7 de septiembre y algunos de sus principales columnistas, como Juan Bravo Murillo, Manuel Pérez Hernández y Joaquín Francisco Pacheco, acabaron siendo expulsados y confinados fuera de Madrid. Además, como durante el dominio de esta fuerza conservadora se había producido una importante sustitución empleados públicos, la Junta les exigió para evitar la remoción el reconocimiento como legítima autoridad. El 12 prohibió a éstos y a todas las autoridades la obediencia al Gobierno moderado de Valencia y ordenó el cierre provisional de todos los Ministerios. Y, finalmente, el 25 creó una comisión para la calificación política, o sea de depuración, de los empleados de todas las dependencias del Gobierno en la provincia, es decir, de toda la administración.

Bien, en la disposición del 12 de septiembre se señalaba que el objeto del pronunciamiento, y de la Junta que lo encabezaba, era salvar el texto constitucional de "los ataques del despotismo," a los asimilaban los anteriores, pero también de "los excesos de la anarquía." Es decir, que la insurrección tenía unos límites por la siniestra, que en Madrid estaba representada por el periódico democrático y republicano El Huracán. Así sus números 71 y 72 de los días 2 y 3 de septiembre fueron denunciados, y el segundo vio suspendida su circulación, por publicar sendos artículos en los que, entre otras cosas, se ponían en cuestión a la Regente y a la forma de gobierno monárquica. Si esta decisión fue recibida con gran satisfacción de los jefes y oficiales de la milicia madrileña, más aún lo sería la noticia sobre los fallos de los jurados de la acusación, resolviendo en ambos casos que había lugar a la formación de causa, y de la calificación, declarándolos subversivos y condenando a su editor, Diego José del Mazo, a 6 y 4 años de prisión, respectivamente. Parece que esta vez los egregios progresistas que constituyeron estos jurados, desde la cercanía del poder, vieron el ejercicio de la libertad de imprenta desde una perspectiva algo diferente. Algo similar aconteció con una tertulia pública patriótica que se quiso celebrar en la capilla de San Isidro porque, al sobrepasar el liberalismo admisible, no fue autorizada por el jefe político. Y, si atendemos a José Segundo Flórez, Juan Lasaña también mantuvo bajo un estricto control a la sociedad masónica de los carbonarios que, con propuestas democráticas y republicanas, estaba muy centrada en las aspiraciones políticas de Luis González Bravo, su cabeza rectora ${ }^{8}$.

8 Para el desarrollo del pronunciamiento hemos seguido: A. G. P., Reinados, Fernando VII, 15/13 y 17/10 y 11 informes policiales y del jefe político de Madrid a la regente, septiembre de 1840; A. V. M., Secretaría, 3/385/70 y 75, y libros de acuerdos del Ayuntamiento, núm. 275, sesiones de septiembre de 1840; Gaceta de Madrid, 3, 5, 6, 7, 11,13 y 15 de septiembre, núm. 2.133, 2.135, 2.136, 2.137, 2.145, 2.147 y 2.150; El Correo Nacional, Eco de Comercio y El Huracán, septiembre de 1840; Revista de Madrid, II (1840), crónicas de los 


\section{Las caras del Madrid insubordinado}

Igualmente superaban la finalidad del pronunciamiento, por lo menos para el grupo que lo acabó liderando, las tendencias federalistas, que acogían esa sociedad y el diario citado anteriormente, pero también la propuesta apadrinada por un sector de los sublevados de establecer una junta central que, retomando el modelo arbitrado en 1808 , se quería estuviese formada por representantes de todas las Juntas provinciales. Con algunas de éstas se puso en contacto el 9 de septiembre la Junta provisional de gobierno de la capital con el objeto de que asumieran el programa por ella consignado, representaran al duque de la Victoria expresando su inquebrantable adhesión constitucional y se armaran para su defensa. Pues bien, por la dilatación nacional y conversión de esta junta en una central eran partidarios los miembros del Ayuntamiento y Diputación provincial de Madrid, que no formaban parte de ella. Lo eran porque, siguiendo la iniciativa de la Junta de Burgos, veían en la centralización de la dirección y del movimiento un medio para acelerar el triunfo del pronunciamiento, evitar los peligros de la divergencia y confusión, y garantizar mejor la uniformidad, generalidad y obediencia de las disposiciones; pero eso sí, era imprescindible que se "admitiera en su seno como partícipes de su autoridad y representación a los comisionados que enviaran las provincias que habían seguido el noble ejemplo de la capital."

Esta propuesta de formación desde abajo de una junta central, generó un importante debate en la prensa, en las tertulias de los cafés y en los círculos políticos, hasta el punto de dividir la cabeza rectora del pronunciamiento en torno a dos posiciones divergentes. Una, la más avanzada, era la que seguía los planteamientos de esas corporaciones madrileñas con uno de los alcaldes, Joaquín María López, al frente. Fue la que la efectuó el llamamiento a las provincias para que nombraran comisionados que se sumaran a la Junta y hacerla central, y también la que arbitró que, mientras tanto éstos llegaban, fueran los residentes de ellas en Madrid los que las representaran (como ocurrió en las Cortes de Cádiz). Encontrándose también entre sus filas Fermín Caballero, dentro de esta tendencia se daba cabida, siguiendo la corriente progresista doceañista, a reivindicaciones de reforma constitucional en un sentido democrático.

La otra posición, más conservadora e institucional, era la que preconizaba la propia Junta provisional y, de manera sobresaliente, su presidente Joaquín María Ferrer en estrecha relación con el general Baldomero Espartero. Así, a pesar de haber sido la primera en dar ejemplo -significaba esta junta- era "ajena a cualquier idea de exclusivismo y preponderancia," pero tampoco apadrinaba la creación de una junta central porque creía que no contaba con facultades para ello y por las grandes dificultades que, a su juicio, presentaba tal propuesta. Por eso, aunque no quisiera entrar a "cali-

meses de agosto, septiembre, octubre y noviembre pp. 53-88. La bibliografía básica en: Detalles históricos del célebre pronunciamiento de Madrid, el $1^{\circ}$ de septiembre de 1840, Madrid, Boix, 1840, vol. I, pp. 1-215; FLÓREZ, José Segundo: Espartero...vol. III, pp. 654-667, 706-709 y 782-784; y Reseña histórica del glorioso alzamiento de 1840... pp. 33-136. También hemos recurrido a: ALCALÁ GALIANO, Antonio: Historia de las Regencias... pp. 254-260; BERMEJO, Ildefonso Antonio: La Estafeta de Palacio. Historia del reinado de doña Isabel II. Cartas trascendentales dirigidas a don Amadeo, Madrid, Imprenta R. Labajos, 1872, vol. I, pp. 663-684; NIDO SEGALERVA, Juan: Historia política pp. 363-366; y PIRALA CRIADO, Antonio: Historia de la guerra civil...vol. VI, pp. 164-183. 
ficar la idea" y planteara consultar a las otras juntas de las provincias, era claramente contraria a su creación y abogaba por el establecimiento en su lugar cuanto antes y desde arriba de un gobierno constitucional.

Pero no valía cualquier ejecutivo. Así ocurrió con el nombrado el 11 de septiembre por la regente en Valencia, el presidido por el progresista Vicente Sancho, que, al no cumplir con las expectativas de la Junta, los escogidos, cuando conocieron su designación, resignaron el encargo. De esta manera se facilitó la que se puede considerar definitiva claudicación de la regente: el 16 de este mes nombraba al general Baldomero Espartero presidente del Consejo de ministros con plenos poderes para tomar las medidas necesarias en aras a lograr la concordia nacional y para elegir a los ministros. Esta vez sí era el Gobierno requerido por la instancia rectora del Madrid pronunciado. Lo era porque, aunque le estableciera como condición sine qua non para dejar las armas el cumplimiento del programa del 4 de septiembre (lo recordamos: reprobación de los ejecutivos moderados y depuración de los funcionarios de Palacio, anulación de proyecto de ley municipal, y disolución de las Cortes y convocatoria de otras con poderes especiales para consolidar el pronunciamiento nacional), ya a través de Manuel Cortina, en calidad de comisionado, la Junta había entrado en negociaciones para el programa y composición del gabinete.

A partir de aquí, se intentaron frenar por todos los medios las acciones indicadas a promover la formación de la junta central. Así, se consiguió que esta propuesta penetrara lo menos posible en la milicia nacional, que manifestó -a través de su primer batallón- su más tajante rechazo contra los que, reunidos principalmente en El Café Nuevo, laboraban en ese sentido. Y, por supuesto, se recurrió al jefe político para que, a través de la policía, impidiera la difusión en la prensa -particularmente El Huracán - los proyectos federalistas y controlara los movimientos y reuniones de las distintas asociaciones republicanas y, especialmente, de los representantes de las Juntas provinciales comisionados en la capital.

Había que contener, como estamos viendo, el desbordamiento revolucionario del pronunciamiento, pero también evitar la pérdida de su carácter y del apoyo popular. Así el pueblo armado en sus distintas maneras que había sido el principal protagonista en la eclosión insurreccional debía seguir creyendo serlo a lo largo de su consolidación. En la tarea primordial de defensa del Madrid insubordinado, a medida que fueron llegando nuevos apoyos militares, que se supo que el ejemplo de la capital había cundido de forma generalizada en las demás provincias y del respaldo otorgado por el duque de la Victoria, se relajó el miedo y el temor ante una posible represión y paulatinamente fue imperando un ambiente cercano al de una fiesta nacional. Derivó en ello espontáneamente, pero también fue propiciado por la Junta provisional, recurriendo al patriotismo liberal bastante arraigado ya con la guerra y con la celebración de los conocidos aniversarios.

Así se pudo constatar en el homenaje brindado al miliciano Pablo Sánchez, muerto en los enfrentamientos armados del primer día del pronunciamiento, pero sobre todo en la gran parada militar del 8 de septiembre a la que, sustituyendo a la sesión pública de los martes del Ayuntamiento madrileño, acudió numeroso vecindario para vitorear a las fuerzas armadas que, incrementadas ya hasta los 26.000 efectivos, desfilaron por sus principales arterias y sellaron sus votos en favor del pronunciamiento. 
Los vivas a la libertad, a la Constitución y a la independencia nacional, las bandas de música y los himnos patrióticos (por excelencia el de Riego) y la iluminación general, presentes en esa celebración, eran algo cotidiano. Como también lo eran las tertulias de los cafés, las comidas de confraternización entre militares y milicianos (principalmente en el Jardín de las Delicias) y las reuniones en las plaza de la Constitución (actual Mayor). Pero donde estos rasgos se sublimaron fue en los homenajes a Baldomero Espartero, héroe popular por excelencia de la insurrección.

El primero de ellos fue el que se llevó a cabo el 12 de septiembre, cuando la Junta dio a conocer el firme compromiso de este general con el pronunciamiento. Acto seguido, las más de 3.000 personas congregadas en las inmediaciones de la Casa de la Panadería estallaron de júbilo en una prolongada fiesta, con los consabidos vítores (también a este general y a la Junta) y bailes nacionales. "La libertad era deidad -señalaba el autor de Detalles históricos del célebre pronunciamiento de Madrid- que presidía" el homenaje y en el que "estaba el pueblo, el verdadero pueblo entregado a sí mismo."

El segundo fue que el organizó el Ayuntamiento con ocasión de su nombramiento como presidente del Consejo. Se desarrolló desde el 29 de septiembre a lo largo de cuatro jornadas de festejos que contaron con desfile militar, serenatas vocal e instrumental, corrida de toros, espectáculo ecuestre, funciones de teatro (dramática y lírica) y banquete de honor. Varias notas destacan de estas celebraciones, empezando por una especie de intento de normalización del proceso insurreccional casi desde el principio. Así, fue el jefe político, en calidad de máxima autoridad gubernativa de la provincia, el que acompañó al ilustre caudillo en el suntuoso carruaje que le llevó por las calles céntricas de la capital. En la recepción en la Casa de la Panadería, la Junta provisional aparecía un tanto engullida por el Ayuntamiento y la Diputación, de las que había salido, que estaban al completo, y el discurso de bienvenida de Joaquín María Ferrer, no estaba muy claro si lo realizaba en calidad de presidente de aquella o como primer munícipe de Madrid. En él, al señalar que "tenían el honor de [recibirle] en el mismo sitio donde el $1^{\circ}$ de este mes se había dado el grito de libertad que resonó en toda España" y que le "habían admirado siempre el valor como guerrero, pero en el día le admiraban aún más como político", se trasladaba la imagen de la conclusión del pronunciamiento y su canalización a la normalidad institucional a través de Baldomero Espartero y el progresismo respetable.

Las crónicas de estos festejos siempre destacan la concurrencia de un inmenso gentío totalmente enfervorizado y junto al homenajeado otorgan un protagonismo principal a la milicia. Así estuvo presente en casi todos los actos, en la sede de la inspección general de este cuerpo, que volvió a estar a cargo del general Valentín Ferraz, se hospedó Baldomero Espartero y en todo momento éste manifestó una especial camaradería con la milicia. En definitiva, se produjo una estrecha identificación entre las obras militar y política de ambos. De esta manera el éxito del pronunciamiento, dando sentido a la existencia de este cuerpo ciudadano como la expresión material del derecho de resistencia a la opresión y de defensa de la revolución, aparece como el logro de la meta liberal perseguida, con la derrota definitiva del absolutismo (en su prolongación carlista) y el triunfo irreversible del régimen constitucional, en los que ocupa un lugar estelar el general Baldomero Espartero. Del mismo modo, se puede 
contemplar en la propia escenografía de la conmemoración con los lemas "Libertad, Independencia Nacional, Constitución y Trono Constitucional" junto a los de "Heroísmo y Patriotismo," y los retratos colocados en transparentes de Isabel II y Espartero junto a los nombres de los mártires por la libertad y lugares de la memoria liberal (Empecinado, Riego, Torrijos...y también Maldonado, Daoíz...; Bilbao, Luchana, Hernani, Zaragoza....). Y, finalmente, todo ello el Ayuntamiento lo quiso rubricar para la posteridad cambiando el nombre de una de las calles más importantes de la capital, la de Alcalá, por el de duque de la Victoria. Por lo tanto, el pronunciamiento, que ahora se da por terminado al ponerse al frente del Gobierno este general y su liberalismo más contenido, se presenta también como la plena realización de la Revolución liberal comenzada en 1808.

Desde esta perspectiva de los que habían asumido las riendas de la insurrección, esta fiesta nacional también tuvo su nota discordante. Fue la que correspondió fundamentalmente a la exposición que el 30 de septiembre entregaron a Baldomero Espartero los representantes de las Juntas de gobierno de distintas provincias promotores de la central. En ella, contemplando el pronunciamiento como una "abierta resistencia" a los "abusos de la autoridad real", requerían, junto a las otras medidas ya solicitadas por la Junta provisional de Madrid, como "primera y principal" la instauración de una corregencia. En este sentido, e incluso yendo más lejos (abogando por la sustitución de la Regencia y por la reforma constitucional), también se pronunciaron en los brindis algunos de los 150 próceres progresistas asistentes a comida celebrada el 2 de octubre en el gran salón del Oriente en honor de ese general.

La integración en el Gobierno, formado al día siguiente, del "alma mater" de la insurrección, Joaquín María Ferrer, otorgándole la vicepresidencia y la responsabilidad de Estado, liberó un tanto a la Junta provisional madrileña, facilitando su acercamiento a las posturas avanzadas de esos representantes de las Juntas de las otras provincias y del Ayuntamiento de Madrid. Con todo, a pesar de tener que trasladarse el nuevo ejecutivo a Valencia a prestar juramento ante la regente, el recién nombrado titular de la Gobernación, el ya mencionado prestigioso jurista y destacado diputado sevillano Manuel Cortina, parece que dejó instrucciones precisas al jefe político de Madrid para impedir tanto la constitución propuesta de una junta central como el deslizamiento al progresismo democrático.

Lo primero Juan Lasaña lo consiguió al prohibir la celebración el 8 de octubre en el salón de columnas del Ayuntamiento de una reunión que, bajo la presidencia del general Evaristo San Miguel, habían programado los comisionados de las juntas provinciales para establecer esa instancia superior. Tampoco se logró en el encuentro alternativo que tuvo lugar en el domicilio de Ramón Calatrava, al que, según $\mathrm{El} \mathrm{Hu-}$ racán, asistieron 30 de los 45 comisionados, siendo un número importante de ellos residentes en Madrid de las provincias a las que representaban, como ocurría, entre otros, con Joaquín María López por Alicante, José María Calatrava por Badajoz y Jaén, Ramón María Lleopart por Barcelona, Fermín Caballero por Cuenca, Pedro Surrá y Rull por Gerona, José Ramón Rodil por Lugo, Mariano de la Paz García por Murcia, Evaristo San Miguel por Oviedo o Juan Bautista Alonso por Vigo. No pudieron dar pasos firmes para la instauración de la junta central porque tanto éstos como los otros comisionados desplazados de otras provincias no contaban con pode- 
res acordes ni en cuanto a las facultades ni cuanto al objeto y, además, se ubicaban en posiciones dispares en el espectro ideológico progresista, lo que provocaba una importante confusión y generaba grandes dificultades para llegar a acuerdos. De ahí que José Segundo Flórez definiera a esta asamblea como "un cuerpo flotante en el borrascoso piélago de la revolución."

Lo segundo claramente resultó bastante más problemático. Por de pronto, la Junta provisional, el Ayuntamiento y los electores parroquiales de la capital coincidieron en perpetuar "la memoria del heroico pronunciamiento", colocando en la fachada de la Casa Consistorial una lápida con la inscripción de "libertad, independencia nacional, $1^{\circ}$ de septiembre de 1840 ", formando una comisión especial encargada de reunir todos los antecedentes y noticias, y señalando a este día como una de las fechas de conmemoración de los madrileños junto al 2 de mayo y el 7 de julio. Recordar, pero también popularizar las celebraciones con comidas patrióticas en el Jardín de las Delicias que, a un precio módico, permitían -subrayaba el autor de Detalles históricos del célebre pronunciamiento- se ampliara el número de los comensales a los artesanos honrados y patriotas, y no se limitara a las aristocracias de partido, e imperaran los "principios latamente populares" del pronunciamiento. Y, desde esta perspectiva, no había que olvidar su sentido y razón de ser originaria: la recuperación del ideario del levantamiento de 1836 o la lectura doceañista de la Constitución de 1837.

A este respecto, la actuación postrera de la Junta provisional no pudo ser más elocuente. De una parte, mediante una circular remitida el 12 de octubre a las otras Juntas provinciales, en la que sostenía que "la soberanía nacional" no sólo había sido el principio de su gobierno, sino que era el "verdadero dogma" del que debía emanar "toda Constitución política." De él se nutría -significaba- "el código de 1837" y, siguiendo el programa de Antonio González, se señalaba que así debía mantenerse en su traslación al gobierno ordinario a través del principio de la soberanía compartida, reduciendo para ello la posición de la Corona en favor de la Cortes e instaurando la responsabilidad ministerial. A esta relectura parlamentaria le acompañaba un avanzado programa de desarrollo político (difusión de la instrucción, extensión y democratización de la desamortización, abolición definitiva de diezmos y primicias, reconocimiento de la deuda, anualidad presupuestaria...), que en cuanto a la ordenación del régimen local -causa principal del pronunciamiento- abogaba por la reforma de la ley de 3 de febrero de 1823, pero rechazando que con ella, como interpretaban los conservadores, "cada Ayuntamiento fuera un foco revolucionario" y manteniéndose dentro del modelo de administración descentralizado, reconociendo la sustantividad del municipio y el gobierno interior al Ayuntamiento.

Y, de otra parte, en esta misma senda, la Junta provisional también se distanció de la senda anterior al sumarse a la exposición que el 15 de octubre los representantes en Madrid de las Juntas provinciales elevaron a la Regencia. En ella, sustentándose rigurosamente en la doctrina del derecho a la resistencia lockiano, se solicitaba la disolución en su totalidad del Senado porque, al igual que los representantes del Congreso, sus miembros eran -se decía- declarados enemigos de la Constitución. Además, a ella, en una suerte de recuperación del espíritu original del pronunciamiento, se incorporaron, primero, el Ayuntamiento de la capital y la Diputación de Madrid, y, después, varios cuerpos de la milicia y, también, algunas juntas de otras provincias. 
Bien, pronosticando esta deriva democrática, el ejecutivo de Baldomero Espartero ya en el programa presentado a María Cristina, se señalaba que, junto a la disolución de las Cortes y no ejecución de la normativa municipal, era imprescindible centralizar el gobierno y hacer cesar las juntas de las provincias porque no era "concebible siquiera que existiera un gobierno en una nación y que juntas provinciales ejercieran sus facultades." También en estas bases de gobierno se establecía la exigencia de responsabilidad a los gabinetes moderados y la instauración de una corregencia formada con "hombres prácticos en la ciencia del gobierno, de talentos acreditados en el parlamento," que acompañaran a María Cristina. Sabido es que no la aceptó y que el 12 de octubre hizo pública su inquebrantable renuncia, embarcándose pocos días después hacia Marsella.

Asumiendo la Regencia el Gobierno de acuerdo con el texto constitucional, prosiguió poniendo en vigor las medidas propuestas con una clara basculación hacia un progresismo bastante templado. Así, distanciándose de la opinión de las juntas, disolvió el Congreso, pero sólo un tercio del Senado, para no infringir -esgrimió- la Constitución; algo que hizo sin mayores miramientos al posponer la reunión de la Cortes, superando los tres meses prescritos, hasta el 19 de marzo del siguiente año. La razón fundamental la situaba el Gobierno en las diputaciones provinciales que, teniendo papel principal en el proceso electoral, estaban disueltas o reemplazadas por las que les precedieron y, además, habían renovadas parcialmente de manera bastante irregular. Por eso el 13 de octubre, al tiempo que suspendía la ley municipal conservadora, se decretaba la elección en su totalidad de las diputaciones.

Esta renovación resultaba también fundamental para la normalización del proceso insurreccional, ya que a estas corporaciones se debían encauzar las juntas de las provincias. Para facilitarlo y porque, como ya lo había señalado el ejecutivo, "la unidad y la centralización bien entendidas eran absolutamente indispensables para gobernar," a partir del 14 de octubre, de estas instancias insurreccionales sólo perduraron las de las capitales provinciales, además, como auxiliares sólo del Gobierno, debiendo remitirle, a través del Ministerio de la Gobernación, noticia circunstanciada de todas las determinaciones adoptadas durante el pronunciamiento.

En Madrid la transformación de la Junta provisional de gobierno en una simple institución auxiliar del jefe político se escenificó el 25 de octubre con su traslado, al tiempo que el Ayuntamiento, de la Casa de Panadería de la Plaza de la Constitución a la Casa Consistorial de la Plaza de la Villa. Acompañados por vecinos y tropas de la milicia y de la guarnición, el acto se convirtió en una conmemoración patriótica, la última de la insurrección, que concluyó con una alocución de la Junta agradeciendo a los presentes por haber cooperado "al triunfo del pronunciamiento más glorioso de cuantos presenta la historia política de las naciones." Desde este momento, retrotrayendo el Gobierno muchas de las medidas tomadas, fue paulatinamente plegando las velas hasta su disolución el 9 de noviembre, anticipándose en dieciséis días al decreto que, dando por terminada la misión de las juntas, disponía su cese.

Por su parte la asamblea de comisionados de las juntas provinciales desapareció con anterioridad sin pena ni gloria, después de haber logrado un acuerdo sobre el manifiesto final de justificación de la conducta observada, que no llegaría a publi- 
carse $^{9}$. En conclusión, por un lado, la división y disparidad de criterios de estos comisionados dificultaron la creación de una junta central y también la profundización democrática del movimiento insurreccional. Por otro lado, igualmente el desarrollo de ambos aspectos lo impidió sobremanera la férrea oposición de la Junta provisional de Madrid, cuyo origen radical y posición de vanguardia muy pronto devinieron en un progresismo más contenido y una total supeditación al general Baldomero Espartero. En definitiva, el glorioso pronunciamiento de septiembre de 1840 tuvo el mismo punto de llegada que la movilización insurreccional de agosto de 1836, el dominio del liberalismo progresista templado de la inclinación doctrinaria de la Constitución de 1837, con el nuevo aditamento castrense ayacucho, y con la mayor difusión de la cultura democrática e incremento de los que propiciaban un reforma del régimen político siguiendo esa orientación.

\footnotetext{
9 Para la normalización del proceso revolucionario hemos seguido: A. V. M., Secretaría, 1/225/14 y 3/385/75y libros de acuerdos del Ayuntamiento, núm. 275, sesiones de septiembre y octubre de $1840 ; E l$ Correo Nacional, Eco de Comercio y El Huracán de los meses de septiembre y octubre de 1840; Revista de Madrid, II (1840), crónicas de los meses de agosto, septiembre, octubre y noviembre pp. 53-88. En cuanto a bibliografía básica a: Detalles históricos del célebre pronunciamiento de Madrid... pp. vol. I $216-236$ y vol. II, pp. 5-344; FLÓREZ, José Segundo: Espartero...vol. III, pp. 680 y 718-724; PIRALA CRIADO, Antonio: Historia de la guerra civil...vol. VI, pp. 184-212 y 586-595; y Reseña histórica del glorioso alzamiento de $1840 \ldots$ pp. 137-293. También hemos recurrido a: BURDIEL, Isabel: Isabel II..., pp. 67-74; CORTINA, Manuel: Breve reseña de las principales disposiciones emanadas del Ministerio de la Gobernación de la Península desde el 9 de octubre de 1840, Madrid, Imprenta Nacional, 1841, pp. 1-18; DÍAZ MARÍN, Pedro: "Espartero: el regente plebeyo" en Emilio LA PARRA LÓPEZ (Coord.), La imagen del poder. Reyes y regentes en la España del siglo XIX, Madrid, Editorial Síntesis, 2011, pp. 177-183; MARICHAL, Carlos: La revolución liberal...pp. 201-203; MOLINER PRADA, Antonio: Revolución burguesa y movimiento juntero en España. (La acción de las juntas a través de la correspondencia diplomática y consular francesa, 1808-1868), Lleida, Ed. Milenio, 1997, pp. 201-203; y PEYROU, Florencia: El republicanismo en España 1840-1843, Cádiz, Universidad de Cádiz, 2002, pp. 56-57, 126-130 y 197.
} 